\title{
Tourists Perceived Value of Forest Experience Base Recreation Based on Fuzzy Entropy Weight
}

\author{
Yi-Tian Jin ${ }^{1}$, Li-Ming Chen $^{1}{ }^{*}$ \\ ${ }^{1}$ College of Economics and Management, China Agricultural University, Beijing, P.R. China
}

\begin{abstract}
This paper constructs a formula for measuring the tourists perceived value index of forest experience base recreation on five dimensions: Scenic resource attachment, Forest cultural experience, Environmental quality perception, "Two mountains" concept identity, and leisure time activities. Taking Bamboo Expo Park Forest Experience Base in Tianhuangping Town, Anji County, Huzhou City of Zhejiang Province as an example, a comprehensive evaluation method based on fuzzy entropy weight is used to evaluate and analyze the tourist perception value index of the Bamboo Expo Park Forest Experience Base recreation. Research shows that the tourist's perceived value index of the base for recreation is 90.92 , revealing that the tourist's perceived value is roughly $10 \%$ off the Bamboo Expo Park Forest Experience Base ticket price.
\end{abstract}

\section{Introduction}

The forest experience base is an essential part of the ecotourism industry chain. Its right ecological environment has good health and wellness functions and educational experience functions [1,2]. How to scientifically and rationally transform the "green water and green mountains" resource and environment elements of the forest experience base into "golden mountains and silver mountains" assets, to not only bring an endless income stream to rural society but also provide tourists with high-quality recreational experience, is an essential topic in the construction of ecological civilization and beautiful villages $[3,4]$. This paper aims to summarize the key elements of the tourist's perceived value of the forest experience base, taking the Bamboo Expo Park Forest Experience Base in Tianhuangping Town, Anji County, Huzhou City, Zhejiang Province as an example. This paper designs a tourist questionnaire, conducted a field survey, and 264 tourists were randomly interviewed on-site. Data related to tourists' willingness to pay for various recreational attributes of the Bamboo Expo Park Forest Experience Base was collected and sorted out. The tourist perceived value index was calculated with a comprehensive evaluation method based on fuzzy entropy to improve tourist-centric service in the base. The reasonable quantitative evaluation of the tourist's perceived value of the forest experience base's recreational attributes is conducive to improving tourist-centric service supply efficiency and enhancing its recreational experience. It has theoretical research value and practical guiding significance to ecological civilization construction.

\section{Research Design}

\subsection{Survey Region}

The Bamboo Expo Park Forest Experience Base is located in Anji County, Huzhou City, Zhejiang Province. As a national 4A-level tourist attraction, a national popular science education base, and the country's first county-level base where giant pandas settled, the forest experience base's current forest coverage rate is $83 \%$, and the environmental quality is good. The region is rich in wild animal and plant resources; more than 50 wild animals, including the national first-class protected animal like the giant panda, the national second-class protected animal like red panda and giant salamander. There are more than 500 wild plant species, including eight rare and endangered plants and three-thousand-year-old ginkgo trees. The high-quality forest environment, abundant wild animal and plant resources, and unique bamboo cultural atmosphere attract many tourists to the forest experience base for sightseeing. It is worth noting that, as a tourist attraction near Yucun, the birthplace of the "two mountains" theory, the forest experience base includes the "two mountains" theory study area such as the two mountains workshop and the two mountains meeting site, which is also an important reason attract tourists for experiential learning. However, as a modern forest experience base, The Bamboo Expo Park Forest Experience Base has significant shortcomings in participatory practice and leisure development. At present, the poor experience an uneven distribution of recreational facilities in the base is an essential factor in restricting tourists from perceiving the forest experience base's

\footnotetext{
Corresponding author: chenliming@cau.edu.cn; 2018311320210@cau.edu.cn
} 
recreational value.

\subsection{The essential items of the perceived value of recreation tourists in the forest experience base}

The Forest Tourism Management Office of the State Forestry Administration defines the forest experience base as based on unique forest resources and environment, provide high-quality ecological publicity and education opportunities and outdoor experience projects, move towards participation, interaction, and fun experience development, meet the needs of humans returning to nature in a specific area [5]. The primary characteristics of the forest experience base are: (1) It has rich forest resources and good forest landscape; (2) It can build a participatory experience economy through forest development; (3) The development goal is sustainable forestry development and harmony between man and nature symbiosis [5].

Based on the analysis of the forest experience base's characteristics, different scholars have divided the forest experience base's recreational value. Li Jiren and Xu Dong (2018) combined the research results and experience of forest health tourism in various countries, based on the analysis of forest health tourism influencing factors, emphasized the importance of scenic resource attachment and environmental quality [6]. State Forestry Administration (2017) believes that forests' cultural value is essential for forest resource accounting, directly related to the people's physical and mental health, quality of life, and happiness index. It points out that forest cultural experience is an essential factor for tourists to choose forest experience base for ecotourism [7]. Zhao Deyu and Zhu Qin (2019) believe that the concept of "two mountains" has dramatically expanded the influence of Anji as its birthplace, and discussed the policy conduction and policy effects of this model, emphasizing the concept of "two mountains" 's importance of a cultural experience in the recreational value system of the forest experience base [4]. Zheng Rumin(2015) selected Kunming Xishan Forest Park as the case study object to analyze the development status of its forest experience; sorted out and summarized the perception, participation, and cognition forms of forest experience activities, pointed out the participation type such as leisure development's importance of practical activities in the development of forest experience [8].

In conclusion, the factors affecting the ecological recreation value of the forest experience base mainly include the following points:

(1) Scenic resources attachment: Resource abundance and scale, resource integrity, resource specificity, resource combination, resource influence, and resource visibility in the forest experience base.

(2) Forest cultural experience: The positive impact and satisfaction the forest brings to human health and spiritual life, including forest education, aesthetics, health, artistic creation, and many other aspects.

(3) Environmental quality perception: Temperature, humidity, height, forest coverage, cleanliness, high yield, noise, surface water quality, and negative oxygen ion concentration in the forest experience base.

(4) "Two mountains" concept identity: Tourists' identification with the cultural concept embodied in the forest experience base, and the expected education; In the Bamboo Expo Park Forest Experience Base, it refers to the ecological protection consciousness cultural identity of the coordinated development of "green water and green mountains" type resources and environmental elements and "The Golden Mountains and Silver Mountains" assets.

(5) Leisure time activities: The participatory practical experience project provided in the forest experience base, using the real environment of the experience activities provided by tourists, in order to create a high-quality forest experience process for tourists.

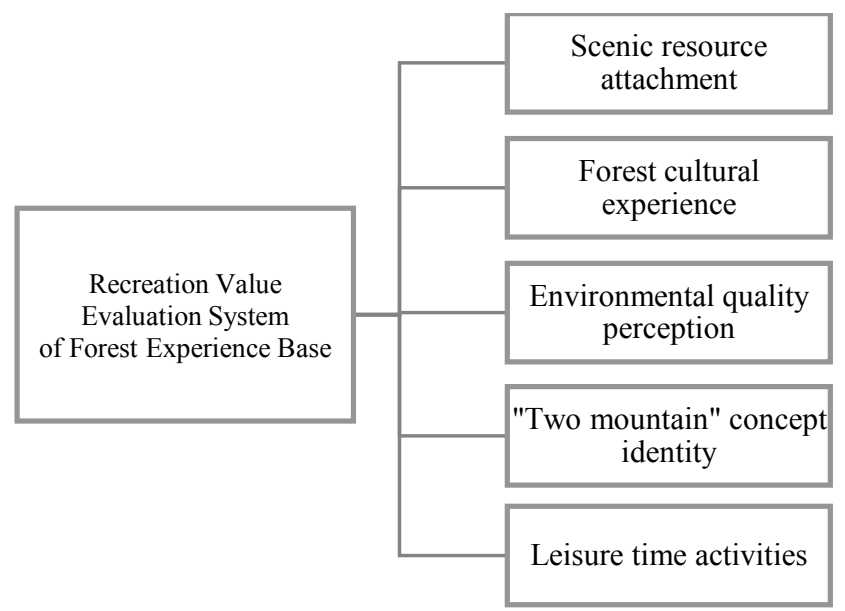

Fig. 1. The essential items of the perceived value of recreation tourists in the forest experience base

Consumers' preference for different recreational attributes of the forest experience base will induce different willingness to pay. The realization of this willingness to pay is purchasing the service value of the forest experience base's different attributes.

\subsection{Research Method- Tourist Perceived Value Index and Its Measurement Based on Fuzzy Entropy Weight}

\subsubsection{Basic concepts}

The entropy concept originated from the second law of thermodynamics, which characterizes the degree of disorder of random movement of molecules, and the corresponding concept of negative entropy characterizes the degree of order. Since entropy has the function of measuring uncertainty and choosing discreteness, Shannon innovatively introduced the concept of entropy into the field of communication in 1948 and used entropy as an essential indicator to measure information uncertainty [9].

The entropy method is a method to determine each indicator's weight based on the amount of information reflected by each indicator in the survey data. The basic principle is the more disorderly and uniform the state of the sample information of an indicator in the evaluation matrix, the larger the entropy value and the smaller the 
entropy weight; On the contrary, the more orderly and uneven the state, the smaller the entropy value. The greater the entropy weight, the more information the indicator can provide, and the more significant the impact on the overall evaluation results [10].

The forest experience base's recreational value is the comprehensive benefit that the forest experience base can provide, integrating economic, ecological, and social benefits. Tourists' willingness to pay can measure the monetary cost that tourists are willing to pay to enjoy the extended recreational attributes of a particular tourist destination called "tourists' perceived value." Regarding the evaluation of the recreational value of tourist destinations, the existing literature either adopts the Travel Expense Method [11,12], or adopts the Conditional Valuation Method [13,14,15], or adopts the Choice Experiment Method [16,17]. This paper attempts to use the fuzzy entropy weight comprehensive evaluation method to calculate the tourist perceived value index based on information entropy.

\subsubsection{The Measurement Procedure of Tourist Perceived Value Index}

The Tourist Perceived Value Index of Recreation in the Forest Experience Base is a weighted synthesis of the tourist's willingness to pay for the recreational value elements in Figure 1. The fuzzy entropy weight is used to give weight to the five categories of entropy-weighted comprehensive recreation. The steps for measuring the tourist perceived value index are as follows.

Step 1. Establish a membership payment matrix:

There are $m$ customers, marked as $Y_{1}, Y_{2}, \ldots \ldots$ 、 $Y_{m} ;$; there are $\mathrm{n}$ recreational attribute indicators, marked as $X_{1}, X_{2}, \ldots \ldots, X_{n}$. The value of the willingness to pay off each tourist under the indicators of various dimensions of recreational attributes constitutes matrix A:

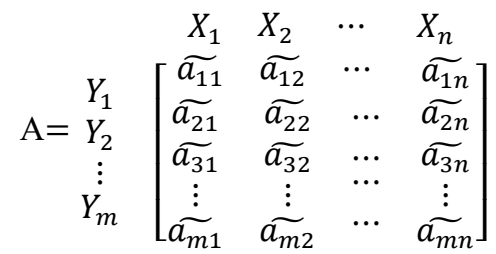

In formula (1), $\widetilde{a_{\imath \jmath}}$ represents the willingness to pay off the $i$-th tourist on the $j$-th recreation attribute index, which is a fuzzy value of the profitability index. Standardize matrix A to get [18]:

$$
R=\left(\widetilde{r_{l \jmath}}\right)_{m \times n}
$$

Where $\tilde{r_{l j}}=\frac{\widetilde{a_{l J}}-\min _{i}\left\{\widetilde{a_{l j}}\right\}}{\max _{i}\left\{\widetilde{a_{l \jmath}}\right\}-\min _{i}\left\{\widetilde{a_{l j}}\right\}}, \quad \widetilde{r_{l j}} \in[0,1]$ is the membership degree of the critical factor of the $i$-th tourist's willingness to pay on the $j$-th recreational attribute index.

Step 2. Calculate the fuzzy entropy value of various recreation attribute indicators:

In a problem with $n$ recreational attribute indicators and $\mathrm{m}$ willingness to pay, the fuzzy entropy of the $j$-th recreational attribute indicator is [10]:

$$
\widetilde{H_{J}}=-k \sum_{i=1}^{m}\left[\widetilde{r_{l \jmath}} \ln \widetilde{r_{l \jmath}}+\left(1-\widetilde{r_{l \jmath}}\right) \ln \left(1-\widetilde{r_{l J}}\right)\right]
$$

Where $i=1,2, \cdots, m$ and when $\widetilde{r_{l j}}=0, r_{i j} l n r_{i j}=$ $0 ; k=\frac{1}{m \ln 2}$ is a constant quantity; $0 \leq \widetilde{H_{J}} \leq 1$.

Step 3. Calculate fuzzy entropy weight:

Entropy is a measure of uncertainty. The smaller the fuzzy entropy value obtained from equation (3), the more reasonable the amount of tourist evaluation information on the corresponding recreational attribute index. Therefore, we obtain the fuzzy entropy weight $\omega_{j}$ on the $j$-th recreation attribute index, which is calculated by equation (4):

$$
\omega_{j}=\frac{1-\widetilde{H_{J}}}{n-\sum_{j=1}^{n} \widetilde{H}_{J}}, j=1,2, \ldots \ldots, n
$$

Step 4. Measurement of Tourist Perceived Value Index Based on Fuzzy Entropy Weight:

The average willingness to pay of $m$ tourists on the $j$ th recreational attribute is defined as the tourist's perceived value of the recreational attribute, denoted as $A_{j}$, see formula (5):

$$
A_{j}=\frac{\sum_{i=1}^{m} a_{i j}}{m}, j=1,2, \ldots \ldots, n
$$

The weighted synthesis of the tourist's perceived value of $n$ recreational attributes based on fuzzy entropy weight is the forest experience base recreational tourist's perceived value index, denoted as TPVI, see equation (6) for details:

$$
T P V I=n \sum_{j=1}^{n} \omega_{j} A_{j}
$$

\subsection{Data Source and Data Processing}

From July 29th to August 1st, 2020, the team members were coordinated by the staff of the local Communist Youth League and County Committee and Bamboo Expo Park Forest Experience Base's staff to conduct on-site interviews with 264 tourists in the two mountains of Yucun and the Bamboo Expo Park Forest Experience Base and dictate the corresponding questionnaire. In this survey, a total of 264 questionnaires were distributed, and 264 were retrieved. Excluding two invalid questionnaires, a total of 262 valid questionnaires were obtained. The effective response rate was $99.24 \%$. The research team members provided the respondents with small gifts as time compensation to increase the respondents' enthusiasm. Besides, under the pre-investigation premise, the research team members summarize the interviewees' general characteristics, optimize and unify the training questioning methods and guidance methods to ensure the reliability of the data obtained. To ensure that the respondents' true willingness to pay is collected, the research team members in this survey preset to distribute 100 units of forest experience coins to each respondent, simulating real payment scenarios. The survey respondents gave real willingness to pay for different recreational attributes, and the real willingness to pay is expressed by the attribute distribution of 100 units of forest experience currency. According to data collection and statistical analysis, the survey effectively collected data from 262 respondents. The statistical description of 
the sociodemographic characteristics of the sample The specific results are shown in Table 1. population was carried out through Stata16.0 software.

Table 1. The statistical description of the sociodemographic characteristic of the sample population

\begin{tabular}{|c|c|c|c|c|c|c|}
\hline Variable & Interpretation & $\begin{array}{c}\text { Number of } \\
\text { observations }\end{array}$ & Mean & $\begin{array}{c}\text { Standard } \\
\text { Error }\end{array}$ & Minimum & Maximum \\
\hline Gender & Male=0;Female=1. & 262 & 0.5076336 & 0.5008986 & 0 & 1 \\
\hline Age & The age group of respondents & 262 & 3.545802 & 1.853805 & 1 & 7 \\
\hline Place & $\begin{array}{c}\text { Huzhou City = 1; Zhejiang Province } \\
\text { (except Huzhou City) =2; Domestic } \\
\text { (except Zhejiang Province)=3; } \\
\text { Overseas =4 }\end{array}$ & 262 & 2.362595 & 0.6268373 & 1 & 4 \\
\hline Education & $\begin{array}{c}\text { Illiteracy=0; elementary school=1; } \\
\text { junior high school=2; high } \\
\text { school/vocational high school=3; } \\
\text { college=4; undergraduate=5; } \\
\text { postgraduate and above=6. }\end{array}$ & 262 & 3.725191 & 1.556366 & 1 & 6 \\
\hline Travel & \begin{tabular}{c} 
How the respondents travel. \\
\hline
\end{tabular} & 262 & 2.167939 & 1.506831 & 1 & 5 \\
\hline
\end{tabular}

Note: The data comes from the research group's field survey, using Stata MP 16.0 for statistical description.

Explanation of variable names: 1. The age range of respondents is defined as (1) under 18 years old $=1$; (2) 19 years old to 25 years old $=2$; (3)26 years old to 30 years old $=3$; 4) 31 years old to 40 years old $=4$; (5)41 years old to 50 years old $=5$; 651 years old to 59 years old $=6$; 7 over 60 years old $=7$.

2. The travel mode is defined as (1) Self-guided tour (travel with family)=1; (2) Self-guided tour (travel with friends)=2; (3) Self-guided tour (travel organized by school)=3; Traveling with a tour group $=5$.

The analysis results show that: Among the 262 interviewees, there are 129 male and 133 female. The average age of the interviewees is 33.64 years old, and the broad age range is wide. In terms of tourists' source, there are more tourists from outside Zhejiang Province, but within the province, Tourists are mainly tourists from outside Huzhou City, and there are few tourists in the city and foreign tourists. It can be seen that the Bamboo Expo Park Forest Experience Base is far away from its urban ecological conservation area and is still mainly used as a target tourist attraction for foreign tourists. In terms of education level, the majority of respondents have a bachelor's degree, followed by a high school degree. The distribution of the respondents' educational background is balanced, and the survey results are representative. From travel methods, self-guided tours with family members account for the vast majority, followed by group tours and self-guided tours with friends.

\section{Research Result}

The statistical description of each variable of the tourist's perceived value index based on fuzzy entropy weight is shown in Table 2.

Table 2. Statistical description of variables of recreational tourist perceived value index based on fuzzy entropy weight

\begin{tabular}{|c|c|c|c|c|}
\hline Variable & Mean & Standard Error & Minimum & Maximum \\
\hline Scenic resource attachment & 26.94566 & 14.78834 & 0 & 100 \\
\hline Forest cultural experience & 20.88548 & 11.13016 & 0 & 100 \\
\hline $\begin{array}{c}\text { Environmental quality } \\
\text { perception }\end{array}$ & 23.82987 & 15.24936 & 0 & 100 \\
\hline $\begin{array}{c}\text { "Two mountains" concept } \\
\text { identity }\end{array}$ & 11.26424 & 11.45909 & 0 & 100 \\
\hline Leisure time activities & 16.39243 & 12.78444 & 0 \\
\hline
\end{tabular}

It can be seen from Table 2 that in the evaluation of consumers' willingness to pay for the five recreational attributes, there is a perfect evaluation of high values, which shows that individual surveyed people pay particular attention to specific recreational attributes. The five attributes' mean value is between 10 and 27 , showing a trend of normal distribution. The recreational attribute with the lowest average value is 11.26 "Two mountains" concept identity, and the highest is the Scenic resource attachment of 26.95, which is in line with subjective perception. The publicity of Bamboo Expo Park Forest
Experience Base is on the concept of giant panda habitat, while the publicity of the "two mountains" theory is slightly weak, and the reason for most tourists come to visit is still to "watch pandas". The standard errors of the five attributes are relatively large, which in a sense reflects the heterogeneity of the perceived value of different tourists.

Using the formula (2-6), we can calculate the Bamboo Expo Park Forest Experience Base's tourist perceived value index. The calculation process data is shown in Table 3.

Table 3. Calculation of tourist perceived value index of recreation in bamboo expo garden

\begin{tabular}{|c|c|c|c|c|c|c|}
\hline Index & Animal & Culture & Environment & Theory & Activity & TPVI \\
\hline$A_{j}$ & 27.1374 & 21.0305 & 23.9962 & 11.3359 & 16.5000 & - \\
\hline$\omega_{j}$ & 0.1230 & 0.1644 & 0.1568 & 0.2990 & 0.2568 & - \\
\hline
\end{tabular}




\begin{tabular}{|l|l|l|l|l|l|l|}
$\omega_{j} A_{j}$ & 3.3390 & 3.4566 & 3.7626 & 3.3899 & 4.2366 & 90.92 \\
\hline
\end{tabular}

Explanation of variable names: (1) Animal represents the scenic resource attachment (2) Culture represents the forest cultural experience (3) Environment represents the environmental quality perception (4)Theory represents the the "two mountains" concept identity (5)Activity represents the leisure time activities.

The Tourist Perceived Value Index of the Bamboo Expo Park Forest Experience Base is 90.92. It shows that tourists' perceived value in Bamboo Expo Park Forest Experience Base is roughly equivalent to a $10 \%$ discount on the ticket price of it. From this, it can be judged that the Bamboo Expo Park Forest Experience Base's recreational experience is still good, but there is still potential for further improvement in tourist experience satisfaction.

\section{Conclusion}

This paper studies and proposes a forest experience-based recreational tourist perception value index and its measurement method based on fuzzy entropy weight. Taking Bamboo Expo Park Forest Experience Base in Tianhuangping Town, Anji County, Huzhou City, Zhejiang Province as an example, we conducted on-site investigations and randomly and effectively interviewed 262 tourists on the spot, distributed questionnaires, and collected and sorted out visitors' comments on various recreational attributes of the Bamboo Expo Park Forest Experience Base. Based on data related to willingness to pay, the evaluation and analysis of the tourist's perceived value of the Bamboo Expo Park Forest Experience Base for recreation are carried out, and the tourist's perceived value index for recreation of the base is 90.92, which reveals that the tourist's perceived value is roughly $10 \%$ off the ticket price of the Bamboo Expo Park Forest Experience Base. A reasonable quantitative assessment of the perceived value of recreational tourists in the forest experience base will help the forest experience base improve the tourist-centric base service supply's efficiency and strengthen the recreational experience effect of tourists. The continuous improvement of the forest experience base's recreational value is inseparable from the multi-faceted coordination of the government, scenic spots, and tourists.

\section{Acknowledgments}

Y.T. Jin thanks the Anji County Youth League Committee of Huzhou City, Zhejiang Province, and the Zhuboyuan Forest Experience Base staff for their enthusiastic help for the research work.

\section{References}

1. Hansen MM, Reo J, Kirsten T. Shinrin-Yoku (Forest Bathing) and Nature Therapy: A State-of-the-Art Review[J]. International Journal of Environmental Research and Public Health, 2017, 14(8 ):851.

2. Pan Yangliu, Zeng Jin, Wen Ye, Yan Qi, Liu Yuanqiu. Research on the suitability evaluation index system for the construction of forest health care bases $[\mathrm{J}]$. Forestry Resources Management, 2017(05): 101-107.
3. Cui Fengjun. Leisure tourism: an important converter between green water and green mountains and golden mountains and silver mountains [J]. Tourism Tribune, 2020, 35(10): 1-3.

4. Zhao Deyu, Zhu Qin. Resource-asset conversion logic: A theoretical explanation of "green water and green mountains are golden mountains and silver mountains"[J].Exploration and Contending, 2019(06): 101-110+159.

5. State Forestry Administration. Notice of the State Forestry Administration on vigorously promoting forest experience and forest health (Linchangfa [2016] No. 3). 2016.

6. Li Jiren, Xu Dong. Research on the construction of an evaluation index system for forest health tourism $[\mathrm{J}]$. Forestry Economics, 2018(3):28-34.

7. State Forestry Administration. Notice of the State Forestry Administration on Printing and Distributing the "Outline of China's Ecological and Cultural Development (2016-2020)". [2017-05-12] http://www.forestry.gov.cn/main/89 /content861381.html

8. Zheng Rumin, Chen Xinfeng, Cheng Xiping, et al. Research on forest experience development based on multifunctional use of forests_-Taking Xishan Forest Park in Kunming as an example[J]. Forestry Resources Management, 2015(05):157-161.

9. Shannon C E. A mathematical theory of communication[J]. Bell system tech. J, 1948, 27.

10. Qiu Wanhua. Management decision-making and applied entropy[M]. Beijing: Machinery Industry Press, 2002.1.

11. Huang Heping, Wang Zhipeng, Lin Wenkai. Evaluation of the damage of tourism resources in scenic spots—-Taking Sanqingshan Giant Mang Peak as an example[J]. Tourism Tribune, 2020(9).

12. Xue Mingyue, Wang Chengxin. Recreation value evaluation of spring-type tourist attractions based on travel cost method--Taking Baotu Spring Scenic Area in Jinan as an example[J]. Journal of University of Jinan: Natural Science Edition, 2020(1): 62- 68.

13. Li Yuxin, Jin Leshan. Research on the recreational value of rural areas based on tourist behavior: Taking Yanqing County, Beijing as an example [J]. Tourism Tribune, 2016, 31(07): 76-84.

14. An Ran, Yang Minfang, Lai Qifu. CVM assessment of the information bias of the recreational value of scenic forest spots[J]. Issues of Forestry Economics, 2020, 40(01):53-59.

15. Yang Shuhao, Gu Xiaoping, Chen Ke. Evaluation of the recreational value of Guanmenshan National Forest Park under the background of rural revitalization[J]. Agricultural Economics, 2019(12): 35-36. 
16. Chen Qin, Huang Qiaolong, Yu Yun, Wei Weijing, Cheng Qiuwang, Zhang Qi. Research on the Economic Value of Forest Park Recreation Based on the Selection Experiment Method-Taking Fujian Province as an Example [J]. Ecological Economy, 2020, 36(06): 124-128+150.

17. Yu Yun, Gong Yuxiang, Huang Qiaolong, Yang Lifan, Chen Ruting, Chen Qin. Evaluation of the recreational value of forest nature reserves[J]. Issues of Forestry Economics, 2020, 40(04): 442-448.

18. Chen Liming, Qiu Wanhua. Fuzzy analysis of factors influencing large-scale project decision-making based on entropy weight [J]. Forecast, 2003, 022(003): 65-67. 